NBER WORKING PAPER SERIES

\title{
ROBUST AGGREGATE IMPLICATIONS \\ OF STOCHASTIC DISCOUNT FACTOR VOLATILITY
}

\author{
Casey B. Mulligan \\ Working Paper 10210 \\ http://www.nber.org/papers/w10210 \\ NATIONAL BUREAU OF ECONOMIC RESEARCH \\ 1050 Massachusetts Avenue \\ Cambridge, MA 02138 \\ January 2004
}

I appreciate the comments of Fernando Alvarez, Lars Hansen, Hanno Lustig, Angelo Melino, seminar participants at the University of Chicago, and the research assistance of Constan Hevia. The views expressed herein are those of the authors and not necessarily those of the National Bureau of Economic Research.

(C2003 by Casey B. Mulligan. All rights reserved. Short sections of text, not to exceed two paragraphs, may be quoted without explicit permission provided that full credit, including (C) notice, is given to the source. 
Robust Aggregate Implications of Stochastic Discount Factor Volatility

Casey B. Mulligan

NBER Working Paper No. 10210

January 2004

JEL No. E21, G12

\begin{abstract}
The stochastic discount factor seems volatile, but is this observation of any consequence for aggregate analysis of consumption, capital accumulation, output, etc.? I amend the standard frictionless model of aggregate consumption and capital accumulation with time-varying subjective probability adjustments, and obtain four implications for aggregate economic analysis. First, subjective probability adjustments add volatility to the stochastic discount factor, and can rationalize any pattern of asset prices satisfying no-arbitrage, even while capital accumulation is efficient. Second, despite its flexibility in pricing assets, the model implies that, in expected value, the intertemporal marginal rate of transformation is equal to the intertemporal marginal rate of substitution, and there is a simple, stable, and familiar relation between consumption growth and capital's return. Third, the expected returns on assets in small net aggregate supply are weakly (and sometimes negatively) correlated with capital's expected return, and are thereby poor predictors of aggregate consumption growth. Fourth, when it comes to assets in small net aggregate supply, capital gains reflect time varying risk premia, and returns can predict aggregate consumption growth better when the capital gain component of those returns is ignored. All four implications are consistent with empirical results reported here, and in the previous literature documenting stochastic discount factor volatility. Several recent theories of stochastic discount factor volatility can, from the aggregate point of view, be interpreted as special cases of subjective probability adjusted CCAPM.
\end{abstract}

Casey B. Mulligan

University of Chicago

Department of Economics

1126 East 59th Street, \#506

Chicago, IL 60637

and NBER

c-mulligan@uchicago.edu 


\section{Table of Contents}

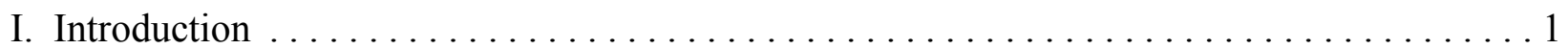

II. SPACCAPM: Adding Subjective Probability Adjustments to the Consumption CAPM . . . 3

The Stochastic Discount Factor Can be Volatile, Conditionally or Unconditionally . . . . . . . . . . . 6

IMRT = IMRS, and There is a Stable Relation Between Consumption Growth and Capital's Return . . . . . 8 8

Assets in Small Net Aggregate Supply have Expected Returns Weakly Correlated with Capital's . . . . . . 11

For Assets in Small Aggregate Net Supply, Capital Gains Reflect Time-Varying "Risk Premia" ........ 13

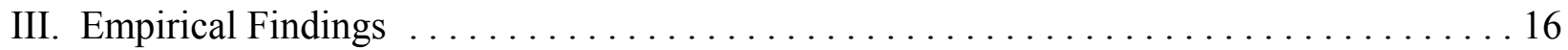

Calibrating the Importance of "Subjective Probability Adjustments" $\ldots \ldots \ldots \ldots \ldots \ldots \ldots \ldots \ldots \ldots \ldots \ldots$

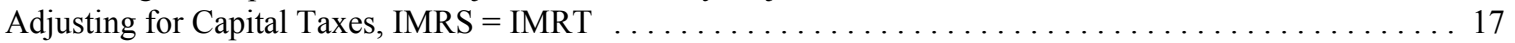

Capital's Expected Return Forecasts Consumption Growth Better Than Other Returns

................................................. 20

Financial Returns Predict Consumption Growth Better When Capital Gains are Deemphasized ......... 23

IV. Models for Which Subjective Probability Adjustments is a Reduced Form . . . . . . . 25

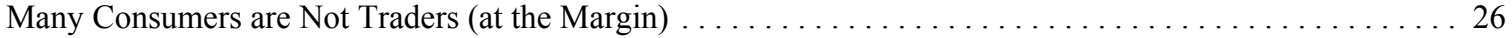

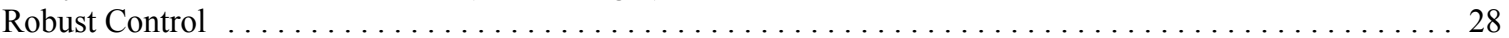

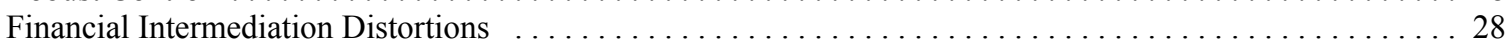

V. Summary and Conclusions . . . . . . . . . . . . . . . . . . . . . . . . . 29

VI. References ..................................... 31 


\section{Introduction}

Asset prices seem to fluctuate over time in ways that are not readily explained in terms of fluctuations in the expectations of asset payoffs, or in terms of general changes in the required rate of return on savings (Campbell and Shiller 1988). Modern finance refers to this phenomenon as (conditional) "stochastic discount factor volatility" because (a) the stochastic discount factor determines the prices of state-contingent claims (it is "stochastic" because there is a separate discount factor for every state of nature), (b) this year's price of a contingent claim can be very different from next year's price of a very similar claim, and (c) macroeconomic models seem to have sharp implications for the stochastic discount factor. Is stochastic discount factor volatility of any consequence for aggregate analysis of consumption, capital accumulation, output, etc.? How?

Attempts to answer these questions can be partitioned in two categories. One category includes He and Modest (1995), and others, who suggest that stochastic discount factor volatility indicates the importance of borrowing constraints and other asset market frictions, which probably implies (among other things) that aggregate capital accumulation is inefficient. Some work in this category, such as Mankiw and Zeldes (1991), Alvarez and Jermann (2001), and Lustig (2003), attempts to explain more precisely the source of asset market frictions, and develop some implications for the wealth distribution, asset price differentials, and other disaggregate observations. A second category of explanations, like those of Constantinides (1990) and Campbell and Cochrane (1999), are based on frictionless market models of more complicated preferences. ${ }^{1}$ These models have more volatile stochastic discount factors even when capital accumulation is efficient, imply a more complicated relation between capital accumulation and the time series behavior of consumption, and have specific implications for asset-price differentials. But when models from either category fail to fit some of the disaggregate observations, there still remains the

${ }^{1}$ Cochrane and Hansen (1992) give an overview of both categories of explanations of stochastic discount factor volatility, and of empirical calculations of its magnitude. 
question of whether other preference modifications or market frictions are creating the stochastic discount factor volatility, and whether the macroeconomic implications would be the same under these alternative environments.

The purpose of this paper is to explore in a more robust way the aggregate implications of stochastic discount factor volatility. Namely, what can be said about aggregate consumption and capital accumulation without saying anything more about the wealth distribution, asset-price differentials, and other disaggregate behavior? Section II obtains four such results, merely by amending the standard frictionless representative agent model of aggregate consumption and capital accumulation with time-varying subjective probability adjustments. First, subjective probability adjustments add volatility to the stochastic discount factor, and can rationalize any pattern of asset prices satisfying no-arbitrage, even while capital accumulation is efficient. Second, despite its flexibility in pricing assets, the model implies that, in expected value, the intertemporal marginal rate of transformation is equal to the intertemporal marginal rate of substitution, and there is a simple, stable, and familiar relation between consumption growth and capital's return. Third, the expected returns on assets in small net aggregate supply are weakly (and sometimes negatively) correlated with capital's expected return, and are thereby poor predictors of aggregate consumption growth. Fourth, when it comes to assets in small net aggregate supply, capital gains reflect time varying "risk premia," and returns can predict aggregate consumption growth better when the capital gain component of those returns is ignored. Section III presents some empirical results confirming these predictions, and reconciles them with previous calculations of stochastic discount factor volatility. Of particular importance is that capital's return is very weakly correlated with bond returns, and forecasts aggregate consumption growth well.

My use of subjective probability adjustments may give the appearance that there are no market frictions, and that all stochastic discount factor volatility derives from complicated preferences. More work needs to be done reconciling subjective probability adjustments with models of asset market frictions, but Section IV recalls the theorems of Harrison and Kreps (1979) and Hansen and Richard (1987), describing the conditions under which assets can be priced by a suitable change in "probability measure" or "adjustment" of the stochastic discount factors. My model might be interpreted as permitting a wide variety of stochastic discount factor adjustments, and hence encompassing many of the special cases satisfying the Harrison-Kreps or Hansen-Richard conditions - including special cases featuring market frictions. Section IV reviews four models from 
the recent asset pricing literature, and shows how they implies some combination of subjective probability adjustments and time preference adjustments, while it is mainly the latter affecting macroeconomic behavior. Section V concludes.

\section{SPACCAPM: Adding Subjective Probability Adjustments to the Consumption CAPM}

Consider a dynamic economy with only a single asset in positive net supply - "capital." Capital earns a time-varying and stochastic return. In each period, there are $S$ possibilities for capital's return, which I index $s=1, \ldots, S$. A dollar of investment in year $t$-1 yields state $s$ gross

return $M_{t}^{s} \equiv e^{m^{s}+\mu_{t}}$ in year $t$, which I decompose into a deterministic component $\mu_{t}$ and a stochastic component $m^{s}$. The states are ordered so that the stochastic component (weakly) rises with $s: m^{1} \leq$ $m^{2} \leq m^{2} \leq \ldots \leq m^{S}$. In order to highlight the main issues, I assume for simplicity that, from the point of view of year $t-1$ (and earlier), the probability of state $s$ 's occurring in year $t$ is $\pi^{s}>0$. I let $E_{t-1}\left({ }^{\circ}\right)$ denote mathematical expectations with respect to this probability distribution. Inormalize the statespecific returns so that $E_{t-1}(m)=0$, and $E_{t-1}\left(\ln M_{t}\right)=\mu_{t}$.

The representative consumer owns the capital, and it is his only source of income. He consumes at each point in time, in the amount $c_{t}$ in year $t$. His preferences are defined over consumption processes $\left\{c_{t}\right\}$, and are recursive over time. In order to characterize his optimal consumption plan, I use the following Bellman equation:

$$
\begin{gathered}
v_{t-1}\left(k_{t-1} M_{t-1}\right)=\max _{c_{t-1}, k_{t}}\left\{c_{t-1}^{(\sigma-1) / \sigma}+e^{-\rho_{t-1}}\left(F_{t-1}\left[v_{t}^{1-\gamma}\left(k_{t} M_{t}\right)\right]\right)^{(\sigma-1) /[(1-\gamma) \sigma]}\right\}^{\sigma /(\sigma-1)} \\
\text { s.t. } \quad k_{t}=k_{t-1} M_{t-1}-c_{t-1} \\
F_{t-1}(x) \equiv \sum_{s} \alpha_{t-1}^{s} x^{s}
\end{gathered}
$$

By using the Bellman equation (1) to characterize optimal consumption plans, I assume that the representative agent's preferences are of the recursive variety studied by Epstein and Zin (1989), with constant intertemporal elasticity of substitution $\sigma>0$, constant coefficient of relative risk aversion $\gamma \geq 0$, and (time-varying) rate of time preference $\rho$. The Bellman equation (1) represents the piece of the optimal plan where the consumer chooses current consumption $c_{t-1}$, and the amount of capital $k_{t}$ to carry into the next period, without knowledge of the capital returns to be realized 
years $t$ and later, but knowing the capital returns realized in the current year $t-1$ and knowing the entire time sequences of the preference parameters.

Three economic ideas are separately embodied in the Bellman equation (1). The first two are "risk aversion" and "intertemporal substitution," which are also emphasized in the work by Hall (1988) and Epstein-Zin (1989). Epstein and Zin point out that equation (1) has "expected utility" as a special case in the limit as the IES $(\sigma)$ approaches the inverse of the coefficient of relative risk aversion $(1 / \gamma)$. Some readers may prefer to think about the expected utility case, or the risk neutrality special case, ${ }^{2}$ because all of my results could be derived there. I have only two purposes for distinguishing $\sigma$ from $1 / \gamma$, or for having risk aversion $(\gamma>0)$ at all: (a) to illustrate exactly how previous models are special cases, and (b) to offer a potentially better understanding of the theoretical results, in particular the degree to which they derive from behaviors motivated by intertemporal substitution rather than risk aversion.

The third, and less familiar, economic idea embodied in (1) is the use of "subjective" rather than objective probabilities. Notice how the "expectation" $F_{t-1}(\cdot)$ is defined as $F_{t-1}(x) \equiv \sum_{s} \alpha_{t-1}^{s} x^{s}$, where strictly positive the parameters $\left\{\alpha^{s}\right\}$ sum to one across states, but vary over time and are not necessarily the same as the mathematical probabilities $\left\{\pi^{s}\right\}$. These properties of the $\alpha$ parameters suggest calling them "subjective probabilities," although this term does not have to be taken literally, and can be perfectly consistent with rationality. Kogan et al (2003, p. 5) have a model with essentially the same $\alpha$ parameters and call it "state dependent utility." 3 The $\alpha$ parameters can also

${ }^{2}$ For $\gamma=1 / \sigma$, we have:

$$
\begin{gathered}
v_{t-1}\left(k_{t-1} M_{t-1}\right)=\max _{c_{t-1}, k_{t}}\left\{c_{t-1}^{(\sigma-1) / \sigma}+e^{-\rho_{t-1}} F_{t-1}\left[v_{t}^{(\sigma-1) / \sigma}\left(k_{t} M_{t}\right)\right]\right\}^{\sigma /(\sigma-1)} \\
\text { s.t. } \quad k_{t}=k_{t-1} M_{t-1}-c_{t-1}
\end{gathered}
$$

To study the risk neutral case, take the Bellman equation above and move the $(\sigma-1) / \sigma$ exponent from the $v_{t}$ term outside the square brackets.

${ }^{3}$ For some other applications of state-dependent utility, see Karni (1985) and Bergstrom (1986). "State dependent utility" has also referred to slightly different preferences, such as Gordon and St-Amour's (2000) where just the risk aversion coefficient varies across states of nature (and is thereby unknown for decision-making purposes). Another example is Melino and Yang's (2003), where the risk aversion coefficient is known for decision-making purposes, but 
be interpreted as state-specific household production parameters, ${ }^{4}$ or attempts to explicitly model specification errors. ${ }^{5}$ The terminology is not important for my purposes (and, along the lines of Gordon and St-Amour 2000, my section IV offers additional interpretations of the $\alpha$ 's), but perhaps “subjective probability adjustment" reminds readers of Harrison and Krep's (1979) theorem, which I discuss further below. The $\alpha$ parameters appear infrequently in the asset pricing literature - and are embraced here - because they put fewer restrictions on the prices of contingent claims. My purpose is to explore some aggregate implications of departures from the relationships implied by the CCAPM developed by Lucas (1978) and Breeden (1979), and extended by Epstein and Zin (1989), without actually explaining the reasons for those departures.

For some purposes it is useful to consider a constant rate of time preference when apply the model to macroeconomic questions, just as it has been for previous applications of the more familiar CCAPM. For now, the Bellman equation (1) features a variable rate of time preference $\rho$, so we can partition the effects of various asset pricing theories into effects on state preferences $\left\{\alpha^{s}\right\}$ and effects on time preference $\rho$.

\section{II.A. The Stochastic Discount Factor Can be Volatile, Conditionally or Unconditionally}

In order to demonstrate the asset pricing implications of the model, I follow the standard practice of allowing the (representative) agents in the model to trade contingent claims in frictionless

evolves over time because it depends on a Markov state vector.

${ }^{4}$ In this case, interpret the program (1) as a reduced form of a model with objective probabilities, and time- and state-specific household production functions. For example, in the two-period case with $\sigma=\gamma=1$, a household's utility would be $\ln z_{1}+\beta \sum_{s=1}^{N} \pi^{s} \ln z_{2}^{s}$, where $z_{1}$ is household production in period 1 , and $z_{1}{ }^{s}$ household production in period 2 and state $s$. Household goods are produced from market purchases according to the state-dependent function $z_{2}^{s}=\left(c_{2}^{s}\right)^{\alpha^{s} / \pi^{s}}$.

${ }^{5}$ A number of macroeconomists, including Parkin (1988), Hall (1997), Mulligan (2002a), and Chari et al (2003), advocate including something like flexible preference parameters in a macro model in order to assess the effect of specifications errors in one market on theoretical implications for other markets, although so far these authors have considered only productivity, time preference, and labor preference shocks. My result is also different than theirs: I find that specification errors in the model's asset markets has essentially no effect on the rest of the model. 
markets. Other than the representative capital good, the contingent claims are in zero net supply. Note that capital returns are assumed to be i.i.d., which means the most general asset pricing implications are only for single-period state contingent claims. This matters for distinguishing capital gains on multi-period securities that were anticipated from those deriving from the revelation of information about payoffs in the distant future, but not for illustrating the four aggregate implications of adding subjective probability adjustments to the consumption CAPM.

A strictly positive stochastic discount factor $q_{t-1}$ can be calculated in the usual way from the equilibrium marginal rates of substitution in the model, and used to price any contingent claim for sale in period $t-1$ and paying off in period $t:^{6}$

$$
q_{t-1}^{s}=\frac{\alpha_{t-1}^{s}}{\pi^{s}}\left(\frac{\left(e^{\sigma \rho_{t-1}} c_{t}^{s} / c_{t-1}\right)^{1-\gamma}}{\left(M_{t}^{s}\right)^{1-\gamma \sigma}}\right)^{1 /(1-\sigma)}
$$

The stochastic discount factor's first term is the ratio of the "subjective" probability $\alpha_{t-1}^{s}$ to the objective probability $\pi^{s}$. I refer to the first term, which would be a Radon-Nikodym derivative if capital's return had a continuous distribution, as the "subjective probability adjustment." In the case studied by Epstein and Zin, the first term is constant over time (and equal to one), so that consumption growth and the return to capital by themselves can be used to price any contingent claim. But in my model the stochastic discount factor has a preference component too, and consumption growth and capital's return cannot be used by themselves to price contingent claims.

The model has enough free parameters that it can price any collection of assets, as long as it satisfies no arbitrage (i.e., that each asset can be priced as a portfolio of primitive state-contingent claims, merely by summing the prices of the components). This result is closely related to those of Harrison and Kreps (1979) and Hansen and Richard (1987). Harrison and Kreps (1979) show how, assuming no arbitrage, assets can be priced (relative to the risk free asset) with risk neutral preferences and appropriate subjective probability adjustments. My model implies that assets can

${ }^{6}$ The reader may be interested in two special cases: relative risk aversion $\gamma$ equal to one and equal to $1 / \sigma$. In the first (second) case, consumption growth (capital's return) is not part of the stochastic discount factor, respectively. 
be priced with CCAPM preferences and appropriate subjective probability adjustments. Or, to put it another way, equation (2) is a decomposition of Harrison-Kreps' subjective probability adjustments (or Hansen and Richard's stochastic discount factor) into a CCAPM term (the term in parentheses) and a residual which itself looks like a subjective probability adjustment. This decomposition is unimportant for asset pricing, but important for macroeconomics.

First, use the state-specific version of equation (4, see below) to eliminate the endogenous consumption variables from the stochastic discount factor expression (2). Second, set the model's stochastic discount factor equal to the Hansen-Richard stochastic discount factor and invert to solve for the $\alpha$ 's. Third, adjust the rates of time preference so that $\alpha$ 's sum to one for each $t$. The third step is important, ${ }^{7}$ because it separates an asset pricing theory's implications for the subjective probabilities from its implications for time discounting. The time discounting implications will be much more important for macroeconomic questions.

By logging (2), we can express the variability over time of the stochastic discount factor as a sum of "subjective probability adjustment" and "other" factors:

$$
\begin{gathered}
\operatorname{var}\left(\ln q_{t-1}\right)= \\
\operatorname{var}\left(\ln \left[\alpha_{t-1}^{s} / \pi^{s}\right]\right)+\operatorname{var}\left(\frac{1-\gamma}{1-\sigma} \ln \frac{c_{t}^{s}}{c_{t-1}}-\frac{1-\gamma \sigma}{1-\sigma} \ln M_{t}^{s}\right)+2 \operatorname{cov}\left(\ln \left[\alpha_{t-1}^{s} / \pi^{s}\right], \frac{1-\gamma}{1-\sigma} \ln \frac{c_{t}^{s}}{c_{t-1}}-\frac{1-\gamma \sigma}{1-\sigma} \ln M_{t}^{s}\right)
\end{gathered}
$$

In the (probability unadjusted) Epstein-Zin case, $\alpha_{t}^{s}=\pi^{s}$ for all $t$, the last two terms in (3) are zero, and the stochastic discount factor is only as volatile as capital's return and consumption growth (as combined according to the risk aversion and intertemporal substitution coefficients). But in general equation (3) shows that the stochastic discount factor can vary a lot more, for example, when the deviation between "subjective" and "objective" probabilities are uncorrelated with consumption growth and capital's return.

The subjective probability adjustments may, or may not, be related to capital's return. Indeed, some theories of asset pricing (eg., Cagetti et al 2002, more on this below) suggest that subjective probabilities should exceed objective probabilities for poor return states, which could add even more volatility through the covariance term. Interestingly, the many of the implications of the

\footnotetext{
${ }^{7}$ See section IV for some illustrations.
} 
covariance term for macroeconomics will be subtle, or even nil, because the subjective probability adjustments have two offsetting effects on macroeconomic behavior (see below).

As shown by Cochrane and Hansen (1992, equation 2.18), stochastic discount factor volatility can be decomposed into conditional volatility and volatility in the discount factor's conditional expectation. My model can be calibrated so that either component dominates. At one extreme is the special case where capital's returns are i.i.d., and the preference parameters $\left\{\alpha^{s}\right\}$ are constant over time, so that consumption growth is i.i.d. and the stochastic discount factor has the same conditional and unconditional means. At the other extreme, capital's returns and the preference parameters $\left\{\alpha^{s}\right\}$ are deterministic and time-varying, so that all of the stochastic discount factor's time variability derives from variability in the conditional mean.

II.B. IMRT $=I M R S$, and There is a Stable Relation Between Consumption Growth and Capital's Return

The intertemporal marginal rates of substitution and transformation depend on the state $s$. Roughly speaking, they are equal in expectation at the time savings decisions are made. More precisely:

$$
E_{t-1}\left[q_{t-1} M_{t}\right]=1
$$

where $M_{t}$ is the intertemporal marginal rate of transformation. Because (under one interpretation) there are no market frictions, the stochastic discount factor $q_{t-1}$ is the inverse of the intertemporal marginal rate of substitution.

Because this is a consumption-based asset pricing model, consumption growth is a determinant of the stochastic discount factor. A simple expression for expected consumption growth can be derived from $(1):^{8}$

${ }^{8}$ Equation (4) can be derived by first guessing that each of the value functions $v_{t}(x)$ takes the form $\varphi_{t} x$, where $\varphi_{t}$ is a constant that depends only on the time sequences $\left\{\mu_{i}, \rho_{i},\left\{\alpha_{i}^{s}\right\}_{s=1}^{s}\right\}_{i=t}^{\infty}$, as described recursively below:

$$
\varphi_{t-1}^{\sigma-1}=1+e^{-\sigma \rho_{t-1}}\left[\varphi_{t}\left(F_{t-1}\left[M_{t}^{1-\gamma}\right]\right)^{1 /(1-\gamma)}\right]^{\sigma-1}
$$




$$
E_{t-1}\left[\ln \frac{c_{t}}{c_{t-1}}\right]=\sigma E_{t-1}\left(\ln M_{t}\right)-\sigma \rho_{t-1}+(\sigma-1) \frac{\ln F_{t-1}\left(e^{(1-\gamma) m}\right)}{1-\gamma}
$$

where $M_{t}$ is the year $t$ gross return on capital accumulated in year $t-1$. The elasticity of expected consumption growth to capital's expected return is, holding constant the probabilities and the preference parameters, the constant intertemporal elasticity of substitution $\sigma$. Equation (4) says that expected consumption growth and capital's expected return move closely together, to the extent that $\sigma$ is close to one and the rate of time preference is constant over time. This is an empirically refutable implication of the SPACCAPM, despite its flexibility in pricing assets, and hence would not be derived from many alternative models of consumption. The purpose of this paper is to see whether and how the core macroeconomic implications of CCAPM might be consistent with asset pricing data.

The consumption growth result can also be understood in terms of the J-statistics (roughly speaking, "fit") of the consumption Euler equations found in the literature. Consider the following conditional moment:

$$
E_{t-1}\left[e^{-\tilde{\rho}_{t-1}}\left(\frac{c_{t}}{c_{t-1}}\right)^{-1 / \sigma} R_{t}^{i}\right]
$$

where $R^{i}$ is the gross return on some asset $i$. In the usual power utility (probability unadjusted) CCAPM, this moment is exactly equal to one for any asset, at least if we interpret $\tilde{\rho}$ as the rate of time preference. In my model, with a minor adjustment to its rate of time preference, this moment

Second, the first order conditions can be used to calculate $c_{t}^{s} / c_{t-1}$. Third, sum across states weighting by the objective probabilities.

At first glance, my equation (4) relating consumption growth to the return on capital is the same as calculated by Epstein and Zin (1991, equation 13). However, the third term is new, and becomes constant over time as $\sigma \rightarrow 1$ or we approach the state independent case $\left(\alpha_{t}^{s} \rightarrow \pi^{s}\right)$ studied by Epstein and Zin. The bigger consequence of subjective probability adjustments is how assets other than capital are priced. 
is exactly equal to one only for the capital stock. The time preference adjustment is:

$$
\tilde{\rho}_{t-1} \equiv \rho_{t-1}+\ln E\left[e^{(\sigma-1) m / \sigma}\right]-\frac{\sigma-1}{\sigma-\sigma \gamma} \ln F_{t-1}\left[e^{(1-\gamma) m}\right]
$$

which is hardly any adjustment as $\sigma \rightarrow 1$.

Now suppose that asset $i$ is a contingent claim paying only in state $i$ at time $t$. Unless this asset $i$ is identical to the capital stock, the conditional moment (5) is not equal to one, and varies over time according to the preference parameter for state $i .^{9}$ To summarize, the state independent power utility Euler equation fits well (and fits perfectly as $\sigma \rightarrow 1$ ) when the return in question is the capital stock. The Euler equation fits worse (and imperfectly even as $\sigma \rightarrow 1$ ) when the asset in question is

in small net aggregate supply.

The subjective probabilities $\left\{\alpha^{s}\right\}$ appear in equation (4)'s last term. An important result for macroeconomics is that, under some reasonable and testable conditions, the last term is pretty constant over time so that the subjective probabilities $\left\{\alpha^{s}\right\}$ are not affecting consumption growth or the relation between consumption and capital returns. Equation (4)'s last term is constant when the preference shocks are uncorrelated with the stochastic component of capital's return. Another reason the last term can be constant (and zero) is $\sigma=1 . \sigma=1$ is critical because the subject probabilities, to the extent they affect the "subjective return" on capital (namely, the return featured in equation (1)), have opposing wealth and substitution effects which exactly offset at $\sigma=1$. With a lower subjective return, consumers cannot afford the old utility level, which is a wealth effect that by itself reduces current consumption and increases capital accumulation. On the other hand, lowering future marginal utility is more costly in terms of foregone current consumption, which creates a substitution effect lowering capital accumulation.

${ }^{9}$ The conditional moment is:

$$
\frac{\pi^{i}}{\alpha_{t-1}^{i}} \frac{F_{t-1}\left[e^{(1-\gamma) m}\right]}{E\left[e^{(\sigma-1) m / \sigma}\right]} e^{(\gamma-1 / \sigma) m^{i}}
$$


II.C. Assets in Small Net Aggregate Supply have Expected Returns Weakly Correlated with Capital's

Although capital's expected return forecasts consumption growth well, the model's subjective probability adjustments imply that capital's expected return will not forecast other asset returns well, and that the other asset prices will not forecast consumption growth well. This can be illustrated by considering the expected returns on contingent claims, or on the risk-free asset. The expected net return from time $t$ - 1 to time $t$ on a contingent claim paying only in state $s$ at time $t$ is $-\ln \left(q_{t-1}^{s}\right):^{10}$

$$
-\ln \left(q_{t-1}^{s}\right)=E_{t-1}\left(\ln M_{t}\right)+\gamma m^{s}+\ln F_{t-1}\left[e^{(1-\gamma) m}\right]-\ln \frac{\alpha_{t-1}^{s}}{\pi^{s}}
$$

The first term on the right hand side is capital's expected return. The last three terms are a combination of risk aversion and subjective probability adjustments, and might therefore be interpreted as a "time varying risk premium." Notice how the subject probabilities, and the risk aversion coefficient, appear in equation (6) but might not appear in Equation (4). These parameters have a lot more to do with asset pricing than with consumption and capital accumulation.

If there were no subjective probability adjustments, as in the standard CCAPM, the "risk premium" represented by the last three terms would be constant over time. It follows that this asset's expected return would be perfectly correlated with capital's expected return, and thereby a good predictor of consumption growth. ${ }^{11}$ Since any asset can be interpreted as a portfolio of assets like the one above, it follows that any asset's expected return should be a good predictor of consumption growth. Perhaps this is the reason why previous studies of consumption, like Summers (1982) and Hall (1988), paid little attention to the choice of asset whose return would be used to

${ }^{10}$ Throughout the paper, "net return" refers to the log of the gross return.

${ }^{11}$ The standard CCAPM can generate an imperfect time series correlation between expected returns on capital and contingent claims by having time-varying consumption risk properties of the capital stock (which for simplicity I have ruled out by not indexing $m$ 's by time). However, unlike the model with subjective probability adjustments, the risk adjustments needed in this case to explain the times series of the excess expected return of capital over other assets is just a function of consumption behavior, as summarized by the consumption Euler equation. 
forecast consumption growth.

But the point of this paper is to explore the implications of the subjective probability adjustments needed to match observed stochastic discount factor volatility. Since the contingent claim expected return is just the log of the inverse of the stochastic discount factor, whatever subjective probability adjustments contribute to the volatility of the stochastic discount factor, they contribute to the volatility of expected contingent claim returns in the same amount. Much of the variation over time in an asset's expected return may be attributed to subjective probability adjustments rather than capital's expected return, and hence have little to do with consumption growth, unless that asset's payoffs closely match capital's payoffs state-by-state. Some asset prices will predict consumption growth better than others; the assets whose prices are poorer predictors will have payoffs not closely matching capital's state-by-state, and thereby be in small net aggregate supply. ${ }^{12}$

Even thought the risk free asset has state-independent payoffs, its expected return will be weakly - and even negatively correlated - with capital's unless capital also happens to be a risk free asset. The price of the risk free asset is just the expected value of the stochastic discount factor. If we denote the risk free asset's gross return as $L_{t}$, we have:

$$
\ln L_{t}=E_{t-1}\left(\ln M_{t}\right)-\ln F_{t-1}\left(e^{-\gamma m}\right)+\ln F_{t-1}\left(e^{(1-\gamma) m}\right)
$$

In words, the risk free rate promised in year $t$ - 1 for maturity in $t$ depends on (a) capital's one-period expected return $E_{t-1}\left(\ln M_{t}\right)$, (b) the current subjective probabilities $\left\{\alpha_{t-1}^{s}\right\}_{s=1}^{S}$ (remember that $F$ is defined with respect to the $\alpha$ 's), (c) the coefficient of relative risk aversion $\gamma$, and (d) the riskiness of capital $\left\{m^{s}\right\}$. If utility were had no subjective probability adjustments, $F$ would be constant over time and the expected return to capital would move in parallel with the risk free rate.

But with time-varying subjective probability adjustments the last two "risk premium" terms in (7) vary over time, and the risk free rate is a poor proxy for capital's expected return. Indeed, the subjective probability adjustments can lead to a negative correlation between consumption growth

\footnotetext{
${ }^{12}$ Hereafter, I refer to an asset whose payoffs do not closely match capital's payoffs stateby-state as "an asset in small net aggregate supply."
} 
and the risk-free rate. To see this, first use the model with $\gamma=1$ to calculate the coefficient $\sigma_{L}$ of a time-series regression of consumption growth on the risk free rate:

$$
\sigma_{L}=\theta \sigma+\lambda(\sigma-1)
$$

The weights $\theta$ and $\lambda$ are complicated functions of time series variances and covariances. I leave it to the reader to show that, when the time-series $\left\{\mu_{t}, \rho_{t},\left\{\alpha_{t}^{s}\right\}_{s=1}^{s}\right\}$ are mutually independent, both weights are in the interval [0,1], and do not necessarily have to sum to one. Furthermore $\theta=1$ and $\lambda=0$ only in the special case that there are no taste fluctuations.

A negative correlation between consumption growth and the risk free rate can occur because subjective probability adjustments have opposing wealth and substitution effects on consumption growth. An increased preference for the bad states (modeled, for example, as $d \alpha^{1}=-d \alpha^{S}>0$ ) drives down the risk free rate. This preference change also reduces the "subjective return" on capital (namely, the return featured in equation (1)) without affecting the actual return on capital. The wealth effect of the subjective return reduction dominates with $\sigma<1$ and the intertemporal substitution effect dominates with $\sigma>1$.

\section{II.D. For Assets in Small Aggregate Net Supply, Capital Gains Reflect Time-Varying "RiskPremia”}

As shown by equation (6), the expected return on any asset can be decomposed into a sum of capital's expected return and a "risk premium." Because the risk premium drives a wedge between the asset's expected return and capital's expected return, it is a nuisance when it comes to forecasting capital's return or consumption growth. For a similar reason, capital gains may also be the same kind of nuisance.

To illustrate this, we now consider a multiperiod security $i$ which is purchased at time $t-1$ for price $p_{i, t-1}$, pays (possibly) state-contingent "profits" $d_{i t}$ in year $t$, and has (possibly) state contingent payoffs in the years $t+1, t+2$, etc. ${ }^{13}$ These securities have a one period expected net return that is

${ }^{13}$ As noted above, capital shocks in the model are i.i.d., so the model does not offer fully general pricing of multi-period securities. Nevertheless, we can explore some of the implications of state dependence (as opposed to state independence) for such pricing. $d_{i t}$ is sometimes called a "dividend," but I avoid that term in order to emphasize the link 
also a sum of capital's expected net return and a risk premium. Furthermore, the same expected net return can be decomposed into expected "profit" and an expected capital gain:

$$
\begin{aligned}
& \text { one period expected net return }= \\
& E_{t-1}\left(\ln M_{t}\right)+(\text { risk premium })_{t-1}=E_{t-1}\left[\ln \left(d_{i t} / p_{i, t}+1\right)\right]+E_{t-1}\left(\ln p_{i, t} / p_{i, t-1}\right)
\end{aligned}
$$

If the expected profit rate were closely correlated with capital's expected return, then the expected capital gain would be closely correlated with the risk premium and thereby be a nuisance when it comes to forecasting capital's return or consumption growth. This exaggerates matters a bit because, while it seems plausible that profits might be determined by the marginal product of capital and have little to do with risk premia, ${ }^{14}$ the price $p_{i, t}$ used to deflate the profits reflects a risk premium. ${ }^{15}$ Nevertheless, a close relation between the profits $d_{i t}$ and capital's return means that the expected capital gain has hardly anything to do with capital's return and a lot to do with time varying risk premia.

Consider a concrete example. Let $p_{\delta, t-1}$ denote the time $t-1$ value of a firm whose only asset is one unit of the capital stock and whose only liability is one period risk free debt whose principal and interest add to the amount $\delta<1$. Clearly this firm will be worth 1 (the price of the capital stock at each point in time) at time $t$ once its debt is paid off and its year $t$ profits have been distributed, and is worth $1-\delta L_{t}^{-1}$ at time $t-1$. Now consider two measures of the expected net return to owning this firm between times $t-1$ and $t$. The first measure $r_{\delta, t-1}$ is simply the log of the ratio of the time $t$ value of the firm (inclusive of the profits earned at time $t$, and net of the principal and interest $\delta$ paid to bondholders) to the time $t-1$ value of the firm $p_{\delta, t-1}$. The second measure $\hat{r}_{\delta, t-1}$ takes the first measure and subtracts the capital gain $\ln \left(1 / p_{\delta, t-1}\right)$ :

between the marginal product of capital and the income flows from securities.

${ }^{14}$ Remember that we have "macroeconomic" applications in mind. This rules out, for example, high frequency applications like ex-dividend day pricing (obviously day-to-day fluctuations in dividend payments have nothing to do with capital's marginal product).

${ }^{15}$ Security $i$ may even give the most information about capital's return if we ignore the capital gain and deflate the earnings by a moving time-average of $p_{i, t}$ - (in finance jargon) something like the ratio of (earnings +interest) to book value! 


$$
\begin{gathered}
r_{\delta, t-1}=E_{t-1}\left[\ln \left(M_{t}-\delta\right)\right]+\ln \left(1-\delta L_{t}^{-1}\right) \\
\hat{r}_{\delta, t-1}=r_{\delta, t-1}-\ln \left(1-\delta L_{t}^{-1}\right)=E_{t-1}\left[\ln \left(M_{t}-\delta\right)\right]
\end{gathered}
$$

The first expected return measure $r_{\delta, t-1}$ is usually preferred in finance, because it is the mathematical expectation of the actual return, including both capital gains and cash flows at time $t$. The second return measure $\hat{r}_{\delta, t-1}$ ignores the capital gains anticipated by the owners of the firm, due to the fact that some time $t$ profits will be used to pay off debt. But the formula above shows how the second return is preferable for aggregate time series analysis because it is independent of the statepreference shocks! The actual expected return on a firm like this depends on the nature of preferences in the year it was acquired, and hence would vary from year to year according to variation in state-preferences. This taste variation is not helpful for forecasting consumption growth or the return on capital. ${ }^{16}$ The second expected return $\hat{r}_{\delta, t-1}$ is high (low) during the years when capital's expected return is high (low), regardless of what might be happening to the state-preference parameters.

\section{Empirical Findings}

Above are four or five empirical implications of stochastic discount factor volatility, in the sense that they can be derived from the consumption CAPM only if it is amended with time varying subjective probability adjustments or something similar (see Section IV). How well do the implications match observations of the U.S. economy and financial markets? In order that at least part of my answer be quantitative, I begin by calibrating the variability of the subjective probability adjustments so that they match Hansen and Jagannathan's (1991) calculation of stochastic discount factor volatility, and Cochrane and Hansen's (1992) calculation of conditional stochastic discount factor volatility. In this sense, my first calculation is an abbreviated version of Campbell and

\footnotetext{
${ }^{16}$ Interestingly, the second return measure $\hat{r}_{1, t-1}$ systematically understates the return to capital, even while it better approximates its fluctuations over time. Hence expected capital gains are needed to obtained the best estimate of the time series average return to capital, at least when they are systematically different from zero as in my example.
} 
Cochrane (1999), Alvarez and Jermann (2001), Lustig's (2003) who have quantitatively modeled the economy in more detail (including, for example, more information on the dynamics of consumption, or who participates in financial markets) - which effectively implies that the representative agent has variability of the subjective probability adjustments - and showing that their model's stochastic discount factor may be as volatile as observed.

My paper has a different purpose: to assume that stochastic discount factor volatility has been (or someday will be) explained and derive implications for aggregate consumption, capital, etc. Hence, my next step is to obtain measures of capital returns from the U.S. economy (see Mulligan 2002b) and verify whether those returns comove with financial returns and aggregate consumption as predicted by the calibrated SPACCAPM.

\section{III.A. Calibrating the Importance of "Subjective Probability Adjustments"}

How much state preference variability needs to be added to the consumption CAPM in order to mimic observed volatility? The answer depends in part on assumed values of the risk aversion and intertemporal substitution coefficients ( $\gamma$ and $\sigma$, respectively). ${ }^{17}$ With $\gamma=1$ (and any $\sigma>0$ ), state-independent stochastic discount factor volatility (measured as a standard deviation) is about one third of (the lower bound) of that observed from financial market data. More volatility is possible without subjective probability adjustments when there is more risk aversion, but based on the $\gamma=1$ case it seems that the model needs enough time varying subjective probability adjustments to double the standard deviation (quadruple the variance) of the stochastic discount factor. ${ }^{18}$ From the equation (2) for the stochastic discount factor, we see that quadrupling the variance means having the state-preference parameter contribute $75 \%$ of the variance. Since the expected net return from time $t-1$ to time $t$ on a contingent claim paying only in state $s$ at time $t$ is just $-\ln \left(q_{t-1}^{s}\right)$, this implies that $75 \%$ of the variance of expected contingent claim returns is due to state preference

\footnotetext{
${ }^{17}$ Another part of the answer depends on how one measures stochastic discount factor volatility. Hansen and Jagannathan calculate a lower bound on volatilty; actual volatility may be significantly higher than the lower bound.

${ }^{18}$ See Cochrane and Hansen (1992, Figure 3.2), although note that several of the points they plot are inconsistent with convex Epstein-Zin preferences. It seems from their graph that $\gamma$ $=\sigma=2$ would attain the volatility bound, although that is just the bound and not the actual volatility.
} 
shocks.

Now consider the annual time series regression of consumption growth on the expected net return on asset $i$. For the special case $\gamma=1, \rho$ constant, and the subjective probability adjustments uncorrelated with capital's return, it is easy to calculate the (plim of) the regression coefficient:

$$
\sigma \frac{\operatorname{var}\left(E_{t-1}\left[\ln M_{t}\right]\right)}{\operatorname{var}\left(E_{t-1}\left[\ln R_{t}^{i}\right]\right)}
$$

Note that the intertemporal substitution elasticity $\sigma$ is the coefficient that would be obtained if capital's expected return were used as independent variable instead. Furthermore, as the sum of capital's expected return and a time-varying risk premium, any asset's expected return must vary more over time than capital's expected return. So the empirical question is exactly how much more expected asset returns vary than capital's. Mulligan (2003) the annual time series standard deviation of capital's expected return to be no more than 0.0067 . If we take asset $i$ to be commercial paper, and forecast the real commercial paper return using the promised nominal yield and lags of inflation, $E_{t-1}\left[\ln R_{t}^{i}\right]$ has postwar standard deviation at least 0.026 . This values imply a ratio of 0.066 ! In words: stochastic discount factor volatility implies that consumption growth is one or two orders of magnitude less elastic to expected commercial paper returns than to capital's return!

\section{III.B. Adjusting for Capital Taxes, IMRS $=I M R T$}

Although we do not expect it to fit perfectly, the power utility CCAPM (ie, with no subjective probability adjustments, and constant rate of time preference) Euler equation should fit well only when the return in question is the capital stock. The empirical failures of the CCAPM Euler equation for stock and bond returns is well known (Hansen and Singleton 1983). But consider using annual data 1947-96 on nondurable consumption expenditure and capital's rental rate (see Mulligan 2002b) to obtain GMM estimates of the CCAPM Euler equation for capital's return, using lagged consumption growth and capital rental as instruments. The intertemporal substitution elasticity $(\sigma)$ point estimate is 1.35 , and we cannot reject the hypothesis that $\sigma=1$.

The same data are consistent with a constant rate of time preference, because the Euler equation seems to fit very well. The p-value for the GMM J-statistic is 0.56 . With $\sigma$ near 1 (so that 
the $\alpha$ terms drop from the consumption growth equation (4)) and a well-fitting Euler equation (so that the rate of time preference seems constant), we cannot reject the hypothesis that consumption growth is independent of the degree of stochastic discount factor volatility.

In order to show graphically the CCAPM Euler equation's good fit, consider again the conditional moment (5), where asset $i$ is either the capital stock, commercial paper, or the S\&P 500. The conditional moment can be estimated for each $i$ and each $t$ by using time series regressions one for each asset $i$ - using as regressors the lagged term (5)'s in square brackets, asset $i$ 's lagged return, the lagged promised nominal yield on commercial paper, lagged inflation, and the lagged IMRS. The fitted values for the regression, graphed in Figure 1, are estimates of the time $t$ conditional moment. ${ }^{19}$

${ }^{19}$ For the purposes of the Figure, $\sigma=1.4$, and each asset has its own rate of time preference set so that the time series average of the conditional moment equals $1 . \sigma=1.4$ is the elasticity estimated below, although the Euler equation fits better for the capital stock for a wide variety of $\sigma$ 's.

The regressions predicting equation (5)'s term in square brackets fit well; the p-values for the regression F-statistic are 0.001 or smaller for each of the three assets. 


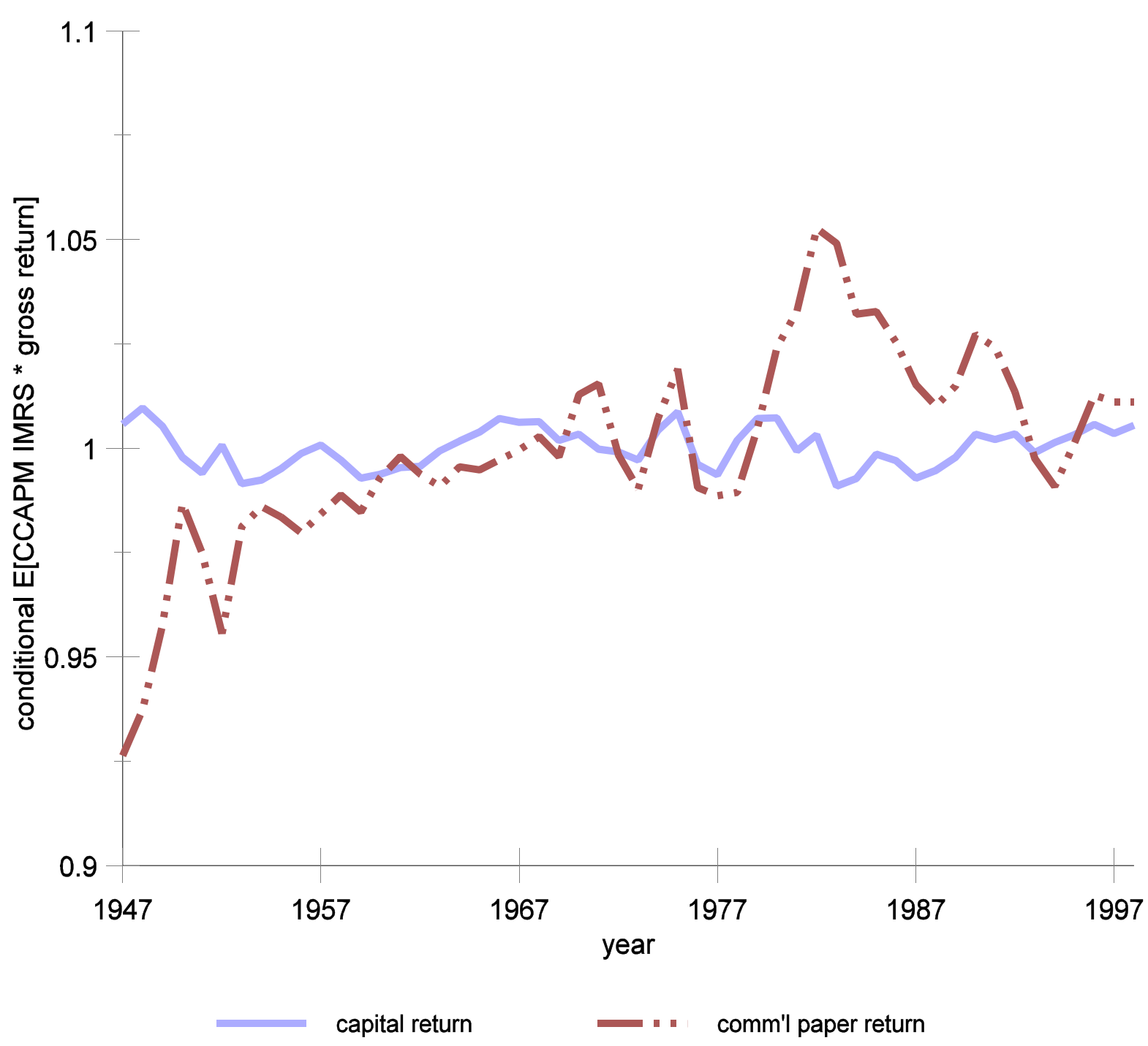

Figure 1 Capital Income Tax Rates: Simulated and Actual

According to the CAPM (with constant time preference rate), the conditional moment is one for all $i$ and all $t$. According to the SPACCAPM (with constant time preference rate), the conditional moment is generally varies over time according to the subjective probability adjustments, except for the capital stock. Figure 1 seems to support the SPACCAPM conclusion. The time series standard deviation of the conditional moment (5) is 0.005 for the capital return, 0.024 for the real commercial paper return, and 0.075 for the S\&P 500 return. The Euler equation fits so poorly for returns measured from S\&P 500, it is not even worth including it in Figure 1.

Remember that, according to the SPACCAPM, the conditional moment (5) exceeds one when in the years people least prefer the states in which that asset pays off well (relative to the 
capital stock). Hence, roughly speaking, the dash-dot series in Figure 1 shows us that people had their strongest preference for commercial paper in the few years after WWII, and their weakest preference in the 1980 's.

\section{III.C. Capital's Expected Return Forecasts Consumption Growth Better Than Other Returns}

Equation (4) is an equation for expected consumption growth as a function of capital's expected return, which can be transformed into an equation for actual consumption growth as a function of capital's actual return by adding and subtracting the usual forecast errors:

$$
\ln \frac{c_{t}}{c_{t-1}}=\sigma r_{t}+\varepsilon_{t}
$$

When derived from my model's equation (4), equation (8)'s $r$ should be interpreted as the net return on capital, and $\varepsilon_{t}$ includes the rate of time preference, and (to the extent $\sigma$ differs from one) the preference shocks represented in the last term in equation (4). When derived from the standard CCAPM (eg., Hall's 1988 equation 1; Attanasio and Weber's 1993 equation 1), equation (8)'s $r$ is the net return on any financial asset, and $\varepsilon_{t}$ includes the rate of time preference but no other preference shock. Under both interpretations, $\varepsilon_{t}$ includes forecast errors so that, if estimated as a regression equation, $r_{t}$ needs to be instrumented with lagged values of economic variables that might be correlated with $E_{t-1}\left(r_{t}\right)$.

Estimates of equation (8) look very different depending on the return measure, and capital's expected return is easily the best predictor of consumption growth. Table 1 reports estimates of the elasticity of consumption growth with respect to an asset return, using 51 postwar annual observations. The specifications differ in two dimensions: the asset for which the return is measured, and the instruments used. Specification (1) is a regression of consumption growth on the real commercial paper return (namely, the nominal yield promised in year $t-1$ minus inflation between $t-1$ and $t$ ), instrumenting using the lagged real commercial paper return. As Hall (1988) found for as similar regression, the return coefficient is economically and statistically insignificant. Although not shown in the table, we cannot reject the hypothesis that consumption growth is uncorrelated with either the current or lagged real commercial paper return. Specification (2) shows how the situation does not change if we add the nominal commercial paper yield, the gap between 
the yields on BAA and AAA bonds, and the lagged inflation rate as instruments. Results do not change significantly if we exchange the commercial paper return for another financial asset return (specifications (3) and (4) do so using the S \& P 500 return). Results are dramatically different if capital's after-tax return is used, as shown in the last two specifications. The elasticity of consumption growth with respect to the return is greater than one, with a $95 \%$ confidence interval (specification (6)) of 0.6 to 2.2. The Durbin-Watson statistics suggest that there may be a little firstorder serial correlation in the residuals, but I show elsewhere (Mulligan 2002b) that various corrections for serial correlation and time aggregation do not change the results. ${ }^{20}$

As I explain above, the SPACCAPM implies not only that consumption's return elasticity is largest when the return measured is capital but, based on Cochrane and Hansen's estimate of stochastic discount factor volatility, also that the consumption return elasticity could be one or two orders of magnitude smaller when a particular financial asset return is used. Table 1 easily shows that there is a one order of magnitude difference between the elasticities reported in specifications (1)-(4) and those reported in (5)-(6), and the difference could be two orders of magnitude.

Specification (6)'s first stage equation (not shown in the Table), which has an adjusted $\mathrm{R}^{2}$ of 0.65 , is interesting. The lagged after-tax return, nominal paper yield, and BAA premium have coefficients of $0.87,-0.07$, and 0.57 (s.e. $=.11, .03$, and .22 , respectively). Notice in particular that high promised nominal paper yields precede declines in capital's rental rate. This is consistent with my thesis that bond yields are not good indicators of the state of demand for capital.

\footnotetext{
${ }^{20}$ It is fairly obvious that time-aggregation corrections should not affect the capital return results, because capital's return series has a fair bit of persistence (it is correlated 0.79 with its lag).
} 


\begin{tabular}{|c|c|c|c|c|c|c|c|}
\hline \multicolumn{8}{|c|}{$\begin{array}{l}\text { Table 1: Asset Returns and Consumption Growth }{ }^{\mathrm{a}} \\
\qquad(1947-97)\end{array}$} \\
\hline \multicolumn{2}{|r|}{ specification: } & (1) & $(2)$ & (3) & (4) & $(5)$ & $(6)$ \\
\hline \multicolumn{2}{|c|}{ independent variable: asset return $r_{t}$} & $\begin{array}{c}0.12 \\
(0.10)\end{array}$ & $\begin{array}{c}0.02 \\
(0.08)\end{array}$ & $\begin{array}{c}0.31 \\
(0.34)\end{array}$ & $\begin{array}{l}0.05 \\
(0.03)\end{array}$ & $\begin{array}{c}1.30 \\
(0.41)\end{array}$ & $\begin{array}{r}1.37 \\
(0.39)\end{array}$ \\
\hline \multicolumn{2}{|l|}{ asset } & \multicolumn{2}{|c|}{ commercial paper } & \multicolumn{2}{|c|}{ S \& P 500} & \multicolumn{2}{|c|}{ capital } \\
\hline \multirow{4}{*}{$\begin{array}{l}\text { instrumental } \\
\text { variables }^{\text {b }}\end{array}$} & lagged return $r_{t-1}$ & $\mathrm{y}$ & $\mathrm{y}$ & $\mathrm{y}$ & $\mathrm{y}$ & $\mathrm{y}$ & $\mathrm{y}$ \\
\hline & nominal comm'l paper yield ${ }^{c}$ & $\mathrm{n}$ & $\mathrm{y}$ & $\mathrm{n}$ & $\mathrm{y}$ & $\mathrm{n}$ & $\mathrm{y}$ \\
\hline & BAA-AAA yield ${ }^{c}$ & $\mathrm{n}$ & $\mathrm{y}$ & $\mathrm{n}$ & $\mathrm{y}$ & $\mathrm{n}$ & $\mathrm{y}$ \\
\hline & lagged inflation rate ${ }^{\mathrm{d}}$ & $\mathrm{n}$ & $\mathrm{y}$ & $\mathrm{n}$ & $\mathrm{y}$ & $\mathrm{n}$ & $\mathrm{y}$ \\
\hline & $\operatorname{adj}-R^{2}$ & .00 & .00 & .00 & .00 & .17 & .17 \\
\hline & Durbin-Watson statistic & 1.50 & 1.48 & 1.54 & 1.48 & 1.83 & 1.77 \\
\hline \multicolumn{8}{|c|}{ 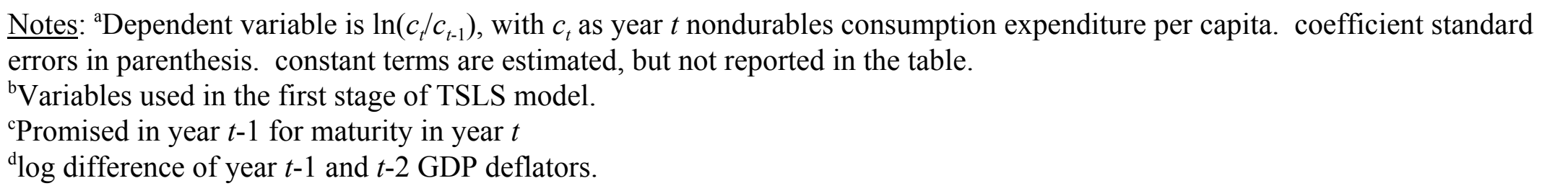 } \\
\hline
\end{tabular}


III.D. Financial Returns Predict Consumption Growth Better When Capital Gains are Deemphasized

Risk premia, and their variation over time, cause the return on a particular asset, especially the capital gain portion of that return, to depart capital's expected return. Hence it should be easier to predict consumption growth if the idiosyncratic capital gains component of an asset's return were deemphasized. One way to do this is to consider returns of larger and larger portfolios. Tables 2 explores this implication. Each row reports coefficient estimates from two consumption growth regressions: one measuring consumption as nondurables and the second measuring consumption as nondurables plus services. The independent variable in each case is the return on the asset in question (which varies by row). TSLS is used, as with Table 1. The first three rows feature the smaller portfolios: "commericial paper," "AAA bonds," and the "S\&P 500." Measuring consumption as the sum of nondurables and services, we see coefficients of 0.13 using the paper return, 0.25 using the AAA bond return, 0.23 using the S\&P composite stock return, and 0.11 using housing returns. 
Table 2: Aggregating Portfolios of Financial and Housing Assets (1947-99)

\begin{tabular}{|c|c|c|}
\hline \multirow[b]{2}{*}{ return measure } & \multicolumn{2}{|c|}{ TSLS ${ }^{\mathrm{a}}$ IES estimate (s.e.) } \\
\hline & $c=$ nondur & $c=$ nondur $+\mathrm{sv}$ \\
\hline real commerical paper return & $-0.03(0.08)$ & $0.13(0.06)$ \\
\hline real AAA bond return ${ }^{\mathrm{b}}$ & $0.22(0.09)$ & $0.25(0.06)$ \\
\hline real S\&P composite stock return ${ }^{c}$ & $0.27(0.22)$ & $0.23(0.16)$ \\
\hline real housing return ${ }^{\mathrm{d}}$ & $0.28(0.15)$ & $0.11(0.09)$ \\
\hline avg of paper \& S\&P returns & $0.34(0.19)$ & $0.32(0.14)$ \\
\hline avg of paper \& S\&P \& AAA & $0.32(0.15)$ & $0.32(0.10)$ \\
\hline avg of housing \& S\&P returns & $0.56(0.42)$ & $0.41(0.27)$ \\
\hline avg of all four returns & $0.54(0.25)$ & $0.48(0.17)$ \\
\hline \multicolumn{3}{|c|}{ 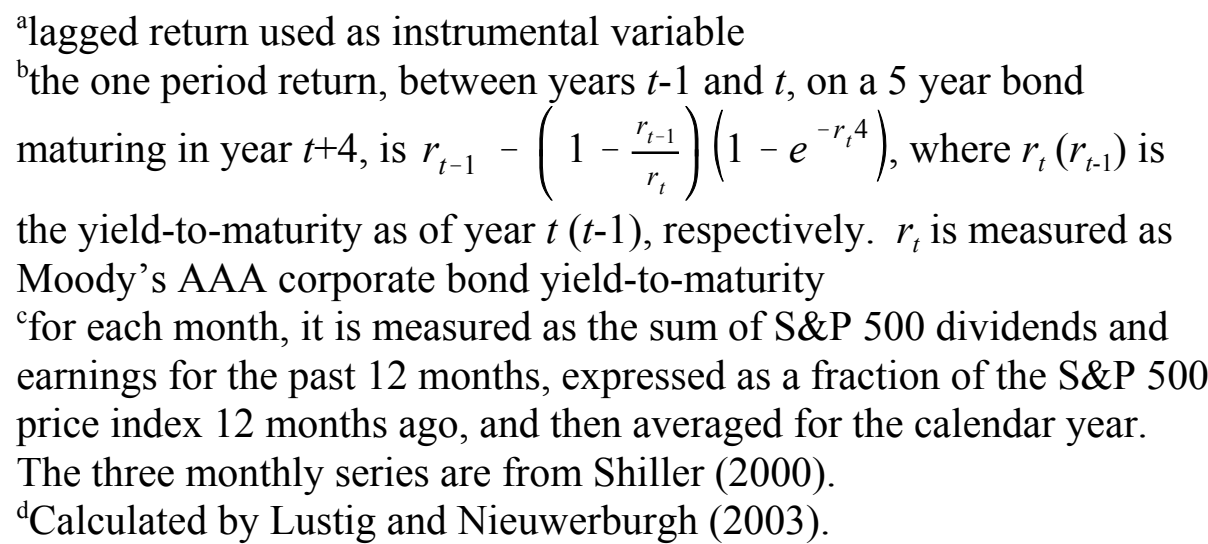 } \\
\hline
\end{tabular}

The next four rows in the Table simply average various return measures, and use the result as a new measure of the return in a consumption growth regression. We see, by comparing the first four rows with the last four, how estimated coefficients on the averages exceed the coefficients on any one of the components. This suggests that portfolio aggregation eliminates the component of the expected return that is idiosyncratic to each asset.

Similar results can be found by looking at the relation between consumption growth and individual stock returns, small portfolios of stocks, and larger portfolio of stocks. Table 9 reports some results for the years 1964-99 (years for which individual stock returns are reported by 
finance.yahoo.com) using GM's stock return, Disney's stock return, and a portfolio of the two. It shows a similar pattern. For example, nondurable consumption growth is more elastic $(0.30)$ to the expected return on a portfolio of GM and Disney stock than to either component's expected return. Nondurable consumption is even more elastic to the full S\&P 500's expected return.

Table 3: Aggregating Portfolios of Stocks

(1964-99)

\begin{tabular}{|c|c|c|}
\hline \multirow[b]{2}{*}{ return measure } & \multicolumn{2}{|c|}{ TSLS $^{\mathrm{a}}$ IES estimate (s.e.) } \\
\hline & $c=$ nondur & $c=$ nondur $+\mathrm{sv}$ \\
\hline real GM stock return & $0.20(0.15)$ & $0.19(0.12)$ \\
\hline real Disney stock return & $0.28(0.92)$ & $0.32(0.98)$ \\
\hline real GM \& Disney stock return & $0.30(0.43)$ & $0.31(0.40)$ \\
\hline real S\&P composite stock return ${ }^{b}$ & $0.32(0.30)$ & $0.29(0.24)$ \\
\hline \multicolumn{3}{|c|}{$\begin{array}{l}\text { alagged return used as instrumental variable } \\
\text { bor each month, it is measured as the sum of S\&P } 500 \text { dividends and } \\
\text { earnings for the past } 12 \text { months, expressed as a fraction of the S\&P } 500 \\
\text { price index } 12 \text { months ago, and then averaged for the calendar year. } \\
\text { The three monthly series are from Shiller (2000). }\end{array}$} \\
\hline
\end{tabular}

\section{Models for Which Subjective Probability Adjustments is a Reduced Form}

The model has enough free parameters that it can price any collection of assets, as long as they satisfy no arbitrage (i.e., that each asset can be priced as a portfolio of state-contingent claims, merely by summing the prices of the components). Under this condition, Hansen and Richard (1987) show that for each period there exists a nonnegative stochastic discount factor that prices all of the assets. In order to calculate the preference parameters $\left\{\alpha^{s}\right\}$ needed to price assets, follow three steps. First, use the state-specific version of equation (4) to eliminate the endogenous consumption variables from the stochastic discount factor expression (2). Second, set the model's stochastic discount factor equal to the Hansen-Richard stochastic discount factor and invert to solve for the $\alpha$ 's. Third, adjust the rates of time preference so that $\alpha$ 's sum to one for each $t$. This section 
illustrates these three steps by example, and shows how the degree to which the rates of time preference have to be adjusted can be related to the magnitude of capital market frictions. Two of the examples also illustrate how "subjective probability adjustments" do not have to be interpreted literally as state-specific preferences at the microeconomic level. ${ }^{21}$

\section{IV.A. Many Consumers are Not Traders (at the Margin)}

A previous literature, including Heaton and Lucas (2000), Alvarez and Jermann (2001), and Lustig (2003), has added various market frictions to the consumption-based asset pricing in order to generate stochastic discount factor volatility. My purpose here is to show how, from the aggregate point of view, these are essentially models of SPACCAPM's subjective probability adjustments. Hence, the aggregate implications derived from state dependent utility apply in those models. Conversely, although superficially "frictionless," my state dependent utility model is consistent with a variety of market frictions, as long as they do not drive a wedge between aggregate consumption growth and the return on a representative piece of capital.

Suppose that the CCAPM model (i.e., the model (1) with state independent utility $\alpha_{t}^{s}=\pi^{s}$ ) applied to each of several types of consumers (indexed $i$ ), who are identical in every way except the type of capital good they accumulate. Consumer type $i$ 's capital return has the same distribution as all other types, just that the realizations differ. ${ }^{22}$ In other words, when the time $t$ state is $s$, some consumers enjoy a high return on capital, and others a low return. There is trade in contingent claims, but only among consumers of the same type. Only the trades of the type $i=1$ consumers take place in the usual financial markets (and thereby observed by the econometrician); these are called the "traders." The stochastic discount factor that prices observed contingent claims is like (2), except that consumption can capital's return must be indexed by $i$, and $\alpha_{t}^{s}=\pi^{s}$ :

$$
q_{t-1}^{s}=\left(\frac{\left(e^{\sigma \rho_{t-1}} c_{1, t}^{s} / c_{1, t-1}\right)^{1-\gamma}}{\left(M_{1, t}^{s}\right)^{1-\gamma \sigma}}\right)^{1 /(1-\sigma)}
$$

${ }^{21}$ Other examples may include Constantinides (1990) and Campbell and Cochrane (1999). Gordon and St-Amour (2000) argue that habit and other complicated preferences may be interpreted as special cases of state dependent utility.

${ }^{22}$ Hence, in this section I discard the assumption that the realizations of the stochastic component of capital's return rises with $s$. 
where the 1 subscripts indicate consumption or capital return by the type 1 consumers.

The stochastic discount factor above can be used to calculate the subjective probabilities for the SPACCAPM analogue (remember that the SPACCAPM model has stochastic discount factor (2) which depends on subjective probabilities, aggregate consumption, and aggregate capital returns). Those subjective probabilities are:

$$
\alpha_{t-1}^{s}=\frac{\pi^{s}\left(\bar{M}_{t}^{s} / M_{1, t}^{s}\right)^{\gamma}}{\sum_{i} \pi^{i}\left(\bar{M}_{t}^{i} / M_{1, t}^{i}\right)^{\gamma}}
$$

where $\bar{M}_{t}^{s} \equiv \sum_{i} k_{i, t} M_{i, t}^{s} / \sum_{i} k_{i, t}$ is time $t$ state $s$ aggregate capital income per dollar of aggregate capital, and aggregate quantities include both traders and nontraders. To the extent that equation (9)'s denominator is different from one, the SPACCAPM analogue also has different rates of time preference.

The time preference adjustments needed for SPACCAPM to mimic aggregate behavior in the traders-nontraders model vary over time to the degree that the expected ratio (shown in the denominator of equation (9)) between the average capital return and the trader's capital return varies over time. ${ }^{23}$ We show above how SPACCAPM's consumption growth depends much more on the rate of time preference than the subjective probability adjustments, so it is important to know what particular asset pricing theories have to say about the rate of time preference adjustment versus the subjective probability adjustments. Furthermore, the aggregate U.S. data seem inconsistent with much time variation in the rate of time preference, which suggests that the more accurate asset

${ }^{23}$ If $\rho_{t-1}$ is the rate of time preference between periods $t-1$ and $t$, the SPACCAPM has rate of time preference below

$$
\rho_{t-1}-\frac{\sigma-1}{\sigma-\sigma \gamma} \ln \left(\sum_{i} \pi^{i}\left(\bar{M}_{t}^{i} / M_{1, t}^{i}\right)^{\gamma}\right)
$$

In the expected utility case, the SPACCAPM rate of time preference is just reduced by the amount of equation (9)'s denominator. 
pricing theories will have little time variation in their implied adjustments to the SPACCAPM's rate of time preference.

Alvarez and Jermann (2001) have a related model in which the identities of the traders change over time. Hence, the subjective probabilities (9) for the Alvarez-Jermann analogue potentially reflect a different consumer type every period. Alvarez and Jermann show that the movement of consumer types in and out of the market may by itself generate enough stochastic discount factor volatility (even with moderate amounts of risk aversion) to match the HansenJagannathan empirical estimates.

Lustig's (2003) model has a continuum of agents, a time-varying fraction of which face a binding solvency constraint. As a result the stochastic discount factor has an additional multiplicative term reflecting wealth distribution changes. This adds volatility to stochastic discount factor, although maybe not enough (Lustig needs to assume a coefficient of relative risk aversion equal to seven). The SPACCAPM analogue to his model therefore has subjective probability adjustments according to changes in the wealth distribution.

\section{IV.B. Robust Control}

Cagetti et al (2002) explain how a savers who are concerned with model misspecification may act as if they overweight the bad states of nature, and predict exactly how much the bad states will appear overweighted. In this regard, robust control theory produces a special case of state dependent utility. My finding that subjective probability adjustments do not have implications for aggregate analysis, aside from the links between asset prices and aggregate behavior, is in this sense a generalization of their finding that "robustness cannot be detected from macroeconomic quantities alone (p. 366)."

\section{IV.C. Financial Intermediation Distortions}

Suppose that contingent claims - including claims on the capital stock - are traded in financial markets, and that their prices satisfy no arbitrage. However, only financial intermediaries, and not consumers, trade in the financial markets. Consumers own the liabilities of the financial intermediaries, which we can call "deposits." Deposits acquired at date $t$ - 1 have one period return $D_{t}^{s}$ in date $t$ state $s$. There are distortions in the intermediation process - perhaps because of monopoly in the market for deposits, regulatory requirements, taxes, etc., so the depositor return is 
$\left(1-\tau_{t}^{s}\right)$ times the return on the intermediary's portfolio.

Because consumers have the usual CCAPM utility functions, the stochastic discount factor in this economy is: ${ }^{24}$

$$
q_{t-1}^{s}=\frac{1-\tau_{t}^{s}}{I M R S_{t}} \Rightarrow \alpha_{t-1}^{s}=\frac{\pi^{s}\left(1-\tau_{t}^{s}\right)}{\sum_{i} \pi^{i}\left(1-\tau_{t}^{i}\right)}
$$

where IMRS is the consumer's intertemporal marginal rate of substitution, without any subjective probability adjustments. Notice how assets can be priced in the same way by the SPACCAPM if the subjective probability adjustments were interpreted as financial intermediary distortions, and the rate of time preference interpreted in part as the expected distortion.

\section{V.Summary and Conclusions}

Cochrane and Hansen (1992) caution that the degree to which macroeconomic models fit asset pricing data may also be related to their capability to reliably forecast the macroeconomic consequences of productivity shocks, fiscal policies, etc. They (and before them Hansen and Jagannathan 1991) explain that current macroeconomic models poorly fit the asset pricing data, and that the poor fit can be summarized in part as stochastic discount factor volatility. My analysis reinforces their warning in one sense, and neutralizes it in another.

As reinforcement of their warning, I emphasize that many macroeconomic models feature limited frictions, and have state independent utility, which implies that all assets are on an equal footing when it comes to forecasting consumption growth, or measuring the marginal product of capital. This implication has many important and practical macroeconomic implications. For example, a weak correlation between consumption growth and the returns on various financial assets might, with the appropriate econometric adjustments for endogeneity, be interpreted as strong evidence of little intertemporal substitution behavior (Hall 1988). Or that the degree of correlation

\footnotetext{
${ }^{24}$ Note that deposits prices do not satisfy no-arbitrage, and cannot be priced with the same stochastic discount factor. Deposit are priced with stochastic discount factor 1/IMRS .
} 
between various financial asset returns and the quantity of government debt is an important indicator of how much government debt crowds out investment. Perhaps as predicted by Cochrane and Hansen, ${ }^{25}$ important conclusions like these change dramatically when a macroeconomic model is amended to account for stochastic discount factor volatility. Namely, when the volatility is generated by time-varying subjective probability adjustments, particular financial asset prices provide very little information about intertemporal marginal rates of substitution and transformation. Interestingly, many of the financial economic theories of stochastic discount factor volatility developed at and since the time of Cochrane and Hansen's writing, are from an aggregate point of view special cases of time-varying subjective probability adjustments.

However, once application of macroeconomic models has been adjusted to avoid sloppy use of the term "interest rate" - namely that the interest rate in aggregate theory is not the promised yield on a Treasury Bill or Bond, but rather the expected return on a representative piece of capital - many of the implications of macroeconomic models may survive the ultimate resolution of asset pricing puzzles. For example, the marginal product of capital may closely follow the intertemporal marginal rate of substitution, and be an important predictor of aggregate consumption growth, regardless of how financial assets are priced. I find strong support for these implications in the $20^{\text {th }}$ century U.S. data. Of course, these are just examples, and more research is needed to determine exactly which kinds of capital market frictions, or exactly which kinds of preference complications, are needed to have an empirically successful asset pricing theory, and what that theory might change about macroeconomics.

\section{References}

Alvarez, Fernando, and Urban J. Jermann. "Quantitative Asset Pricing Implications of Endogenous Solvency Constraints." Review of Financial Studies. 14(4), Winter 2001: 1117-51.

${ }^{25}$ Although note that, at times, they suggest retaining the particular idea that all assets are on an equal footing when it comes to forecasting consumption growth, or measuring the marginal product of capital: "asset prices provide information about intertemporal marginal rates of substitution and transformation" (p. 115). 
Bergstrom, Theodore. "Soldiers of Fortune?” in Walter P. Heller, Ross M. Starr, David A. Starrett, eds. Essays in honor of Kenneth J. Arrow. Volume 2. Cambridge: Cambridge University Press, 1986: 57-80.

Cagetti, Marco, Lars Peter Hansen, Thomas Sargent, and Noah Williams. "Robustness and Pricing with Uncertain Growth." Review of Financial Studies. 15(2), 2002: 363-404.

Campbell, John Y., John H. Cochrane. "By Force of Habit: A Consumption-Based Explanation of Aggregate Stock Market Behavior.” Journal of Political Economy. 107(2), April 1999: 205-51.

Campbell, John Y. and Robert J. Shiller. "The Dividend-Price Ratio and Expectations of Future Dividends and Discount Factors." Review of Financial Studies. 1(3), Autumn, 1988; 195-228.

Campbell, John Y. and Robert J. Shiller. "Stock Prices, Earnings, and Expected Dividends." Journal of Finance. 43(3), July 1988: 661-76.

Chari, V.V., Patrick J. Kehoe, and Ellen R. McGrattan. "Business Cycle Accounting.” Federal Reserve Bank of Minneapolis working paper 625, July 2003.

Cochrane, John and Lars Peter Hansen. “Asset Pricing Explorations for Macroeconomics.” NBER Working Paper \#4088, June 1992.

Cochrane, John H., and Lars Peter Hansen. "Asset Pricing Explorations for Macroeconomics." NBER Macroeconomics Annual 1992. 1992: 115-65.

Constantinides, George M. "Habit Formation: A Resolution of the Equity Premium Puzzle." Journal of Political Economy. 98(3), June 1990: 519-43

Epstein, Larry G. and Stanley E. Zin. "Substitution, Risk Aversion, and the Temporal Behavior of Consumption and Asset Returns: An Empirical Analysis.” Journal of Political Economy. 99(2), April 1991: 263-86.

Gordon, Stephen, and Pascal St-Amour. "A Preference Regime Model of Bull and Bear Markets." American Economic Review. 90(4), September 2000: 1019-33.

Hall, Robert E. "Intertemporal Substitution in Consumption.” Journal of Political Economy. 96(2), April 1988: 339-57.

Hall, Robert E. "Macroeconomic Fluctuations and the Allocation of Time." Journal of Labor Economics. 15(1), Part 2 January 1997: S223-50.

Hansen, Lars Peter and Ravi Jagannathan. "Implications of Security Market Data for Models of 
Dynamic Economies.” Journal of Political Economy. 99(2), April 1991: 225-262.

Hansen, Lars Peter and Scott F. Richard. "The Role of Conditioning Information in Deducing Testable Restrictions Implied by Dynamic Asset Pricing Models." Econometrica. 55(3), May 1987: 587-613.

Hansen, Lars Peter and Kenneth J. Singleton. "Stochastic Consumption, Risk Aversion, and the Temporal Behavior of Asset Returns.” Journal of Political Economy. 91(2), April 1983: 249-65.

Harrison, J. Michael and David M. Kreps. "Martingales and Arbitrage in Multiperiod Securities Markets." Journal of Economic Theory. 2(3), June 1979: 381-408.

He, Hua and David M. Modest. "Market Frictions and Consumption-Based Asset Pricing." Journal of Political Economy. 103(1), February 1995: 94-117.

Heaton, John, and Deborah Lucas. "Stock Prices and Fundamentals." in Ben S. Bernanke and Julio J. Rotemberg, eds. NBER Macroeconomics Annual 1999. Cambridge: MIT Press, 2000: 213-42.

Karni, Edi. Decision Making Under Uncertainty: The Case of State-Dependent Preferences. Cambridge, MA: Harvard University Press, 1985.

Kogan, Leonid, Stephen Ross, Jiang Wang, and Mark Westerfield. "The Price Impact and Survival of Irrational Traders.” NBER Working Paper \#9434, January 2003.

Lustig, Hanno. "The Market Price of Aggregate Risk and the Wealth Distribution.” manuscript, University of Chicago, July 2003.

Mankiw, N. Gregory and Stephen P. Zeldes. "The Consumption of Stockholders and Nonstockholders." Journal of Financial Economics. 29(1), March 1991: 97-112.

Melino, Angelo, and Alan X. Yang. "State Dependent Preferences can Explain the Equity Premium Puzzle." Review of Economic Dynamics. 6(4), October 2003: 806-30.

Mulligan, Casey B. "A Dual Method of Empirically Evaluating Dynamic Competitive Equilibrium Models with Market Distortions, Applied to the Great Depression and World War II." NBER working paper \#8775, February 2002a.

Mulligan, Casey B. "Capital, Interest, and Aggregate Intertemporal Substitution.” NBER Working Paper \#9373, December 2002b.

Mulligan, Casey B. "Capital Tax Incidence: Fisherian Impressions from the Time Series.” NBER Working Paper \#9916, August 2003. 
Parkin, Michael. "A Method for Determining Whether Parameters in Aggregative Models are Structural." in Karl Brunner and Bennett T. McCallum, eds. Money, Cycles, and Exchange Rates: Essays in Honor of Allan H. Meltzer. Carnegie-Rochester Conference Series on Public Policy, 29, Autumn 1988: 215-52.

Summers, Lawrence H. "Tax Policy, the Rate of Return, and Savings." NBER working paper no. 995, September 1982. 